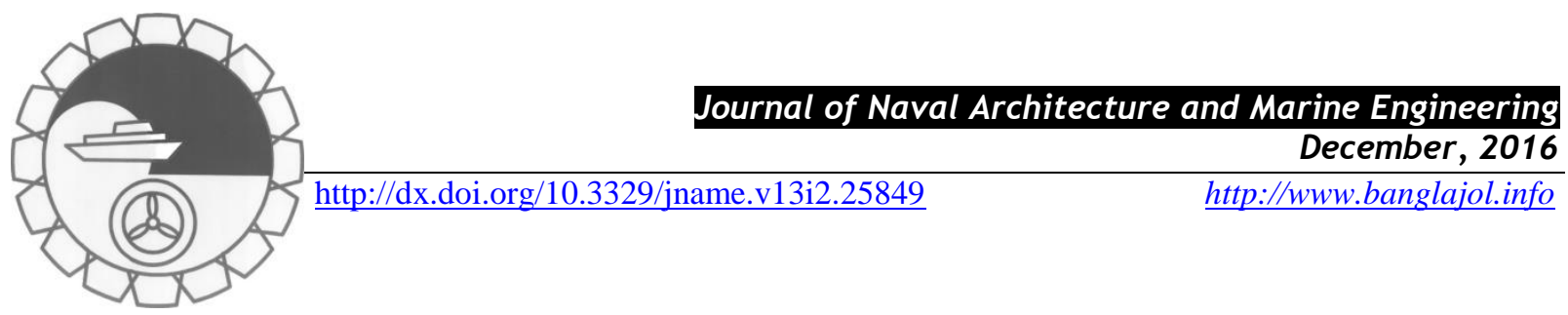

\title{
UNSTEADY CFD SIMULATION OF 3D AUV HULL AT DIFFERENT ANGLES OF ATTACK
}

\author{
S. Ray ${ }^{1}$, D. Chatterjee ${ }^{2 *}$, S. Nandy ${ }^{3}$
} ${ }^{1}$ Department of Aerospace Engineering, Indian Institute of Technology, Kharagpur-721302, India, su43dipta@ gmail.com
${ }^{2}$ Advanced Design and Analysis Group, CSIR-Central Mechanical Engineering Research Institute, Durgapur-713209, India,
rsdchat@gmail.com
${ }^{2}$ Robotics and Automation Group, CSIR-Central Mechanical Engineering Research Institute, Durgapur-713209, India,
snandy35@gmail.com

\begin{abstract}
:
An unsteady, three-dimensional flow simulation is carried out over the bare hull of the autonomous underwater vehicle currently being developed by CSIR-CMERI, Durgapur, India at various angles of attack with the help of a Finite Volume-based CFD software. The purpose of the study is to provide estimation of various hydrodynamic forces acting on the bare hull at different angles of operation. The operating range of velocity of the vehicle is 0 6 knot $(0-3 \mathrm{~m} / \mathrm{s})$, considering up to 2 knots of upstream current. For the purpose of the CFD simulation, the widely-implemented RANS approach is used, wherein the turbulent transport equations are solved using the low-Re version of the SST $\kappa-\omega$ turbulence model. The motion of the vehicle is considered within a range of the pitch angle $\left(0^{\circ} \leq \alpha \leq 20^{\circ}\right)$. The results are presented in terms of variations of the relevant hydrodynamic parameters. The effects of the angle of attack on the drag and pressure coefficients are discussed in detail.
\end{abstract}

Keywords: Numerical simulation, underwater vehicle, pitch angle, turbulence model.

\section{NOMENCLATURE:}

$\begin{array}{ll}A & \text { Reference area }\left(\mathrm{m}^{2}\right) \\ C_{D} & \text { Drag coefficient (-) } \\ C_{D p} & \text { Pressure drag coefficient (-) } \\ C_{D v} & \text { Viscous Drag Coefficient (-) } \\ d & \text { Mid-body diameter (m) } \\ D_{\omega} & \text { Cross-diffusion term for } \omega \\ F_{D} & \text { Total drag force }(\mathrm{N}) \\ G_{\kappa}, G_{\omega} & \text { Generation of } \kappa, \omega \\ H & \text { height of the domain }(\mathrm{m}) \\ I & \text { Turbulent intensity }(\%) \\ l & \text { Length of the hull (m) } \\ L_{d} & \text { Downstream length of domain (m) } \\ L_{u} & \text { Upstream length of domain }(\mathrm{m}) \\ l_{t} & \text { Turbulent length scale (m) } \\ p & \left.\text { Static pressure (Nm }{ }^{-2}\right) \\ R e & \text { Reynolds number }(-) \\ \mathrm{t} & \text { Time (s) } \\ \Delta \mathrm{t} & \text { Time step size (s) }\end{array}$

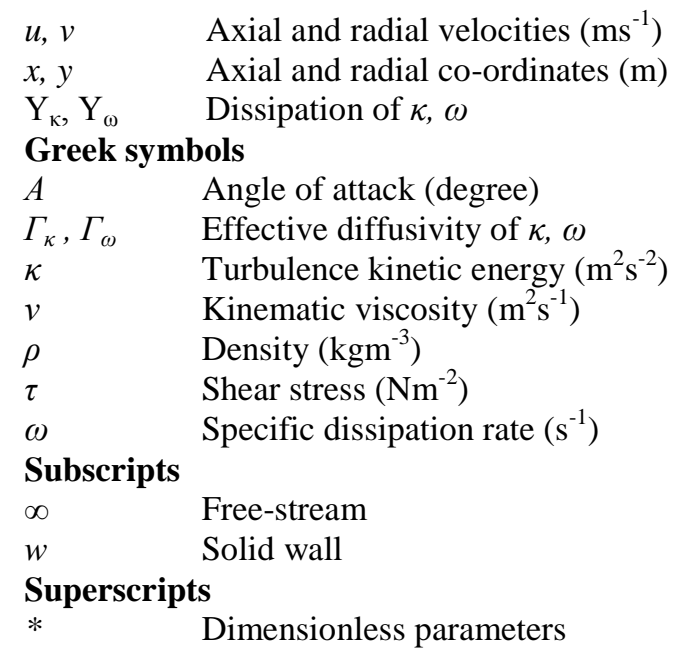

\section{Introduction}

The modeling and simulation of an Autonomous Underwater Vehicle (AUV) and calculations of the pertinent hydrodynamic coefficients have been performed by many researchers for developing technologies related to the unmanned underwater navigation. The commercial applications of an AUV includes sea-bed mapping, testing of 
pipelines and underwater cables, testing the salinity of the sea-water, searching the sea-floor for different minerals etc. Efficient design of an AUV requires accurate estimations of the hydrodynamic coefficients during design of an underwater vehicle at a reduced cost. Several methods have been used throughout the years of development to produce the required estimation of these parameters for a given geometry during the design phase. These methods involve analytical, semi-empirical, experimental model study, system identification-based and computational approaches. Computational Fluid Dynamics (CFD), through the developments in the last few decades, has emerged as the most useful and economical tool to calculate hydrodynamic forces of a marine vehicle. The CFD method is usually cost-effective and less time-consuming than an experimental method, particularly for the different stages of design and testing of an AUV as recommended by Philips et al. (2010).

One of the earlier studies on the underwater hydrodynamics of different axisymmetric bodies; namely AFTERBODY-1, AFTERBODY-2, modified spheroid and F-57 is carried out by Sarkar et al. (1997), keeping in mind the need to find a suitable turbulence closure model. The authors applied the high-Re alternatives of the $k-\varepsilon$ models: standard, the RNG-derived and the Kim and Chen-modified, with wall-law boundary conditions at the body surface. The work of Cairns et al. (1998) proposed the design of AUV propellers on the basis of Blade Element Momentum Theory (BEMT). Baker (2004) performed the 3D simulation of the axisymmetric bare hull of the DREA (Defence Research Establishment Atlantic) submarine by the help of a commercial solver CFX-5 (now Ansys CFX (2009)) using unstructured mesh. The results were compared with the wind tunnel test by Mackay (1988) done on the same submarine model. The study reported the variations of the pressure and viscous drag with different mesh sizes and free-stream flow Reynolds number. To assist the widely-used planarmotion-mechanism (PMM) test for determining the hydrodynamic coefficients, Kim et al. (2002) employed two nonlinear observers- the sliding mode observer and an extended Kalman filter. Jagadeesh and Murali (2005, 2006) reported the comparison between different low-Rek- $\varepsilon$ models for the hydrodynamic modelling of axisymmetric AUVs. The study on the 3D Unmanned Underwater Vehicle (UUV) models by Abdullah et al. (2007) predicted a smoother velocity profile with larger wake for the model without holes for thrusters as compared to the one with holes for the thrusters. Zhang and Wang (2007) carried out the dynamic modelling and analysis of VBS-AUV model using multi-body system dynamics and compared the results obtained from the empirical method with the CFD results. $\mathrm{Hu}$ and Lin (2008) calculated the hydrodynamic forces and stability derivatives within sufficient accuracy in a 3D simulation of the flat-type AUV SMAL01 in a body-fixed reference frame. Philips et al. (2008) performed RANS simulation on the hull with SST turbulence models for the modelling of the hull while separately modelling the propeller using the BEMT (Cairns et al., 1998) approach which showed that the hybrid technique is more economical than modelling the entire vehicle motion using RANS-based method. In a later study (Philips et al., 2010), the same authors satisfactorily represented the much needed pure drift and rotating-arm tests for deriving the hydrodynamic derivatives. Seo et al. (2008) showed the way of applying CFD-based models to examine the performance of an underwater glider by determining the capacity of the buoyancy engine and mass-moving system as a function of the advance speed and the angle of attack. Using the structured mesh, Karim et al. (2008) tested the Shear Stress Transport (SST) $k$ - $\omega$ turbulence model for calculation of viscous drag on several axisymmetric underwater bodies, which include the DREA submarine (Mackay, 1988) and six other axisymmetric bodies of revolution. In a later study (Karim et al., 2011), the authors performed similar type of simulation using unstructured grid. Husaini et al. (2009) used the control volume based commercial code Fluent (now Ansys Fluent, 2009) to simulate the motion of multiple AUVs working in a co-operative manner. The work took into consideration different arrangements of multiple AUVs. A later study (Husaini et al., 2011) reported 3-D simulation of AUV propeller using $k$ - $\omega$ turbulence model for varying ranges of propeller speed and the advance coefficient for parallel development of thrusters control system.

Further developments, on the field, report numerous studies taking into account the motion of underwater vehicles at different angles of attack. Considering fin-body interactions for different sideslip angles, De Barros et al. (2008) performed a comparative study between a CFD-based (SST $k$ - $\omega$ turbulence model) model and the Analytical Semi-Empirical (Allen-Perkins model/ Datcom approach) model of the MAYA-AUV with angles of attack ranging from 5 to $20^{\circ}$. Jagadeesh et al. (2009) made a comparative study between experimental and numerical results, considering flow over AUV hull with different angle of attacks in the range of $0^{\circ}$ to $15^{\circ}$. Sakthivel et al. (2011) numerically studied the cross-flow interactions for 3D flow over the MAYA-AUV under different angles of attack. Non-linear variations of the normal force coefficient were seen at higher angles of attack. Also, the separation point moved towards the nose at higher angle of attack. Gomatam et al. (2012) conducted extensive numerical computations to study the effects of variations in drift angle on the flow past AUVs. The study showed that the presence of the control surfaces and non-zero angles of attack cause nonlinearity in pressure variation at the downstream of the axisymmetric body. The use of air jets to reduce the drag 
in axisymmetric underwater vehicles such as AFTERBODY-1 and a modified blunt AFTERBODY-1 was proposed by Shereena et al. (2013).

In the present paper, the hydrodynamic simulation of the underwater vehicle AUV-150 is undertaken for the purpose of better drag prediction in the design stages. Although the complete estimation of drag would be possible if we consider all the appendages and protruding elements, which contribute to a significant amount of drag, it is still possible to predict the drag force acting on the AUV by considering the bare hull only and adding to it a fractional amount as the appendage drag. For this purpose, we have considered the motion of the vehicle at different angular orientation corresponding to varying incidence angle $\left(0^{0} \leq \alpha \leq 20^{\circ}\right)$ with different surge velocities corresponding to a range of Reynolds number, $1.53 \times 10^{6} \leq \operatorname{Re} \leq 9.18 \times 10^{6}$. The wide range of angle of attack considered here is computationally challenging as the issues such as grid generation and numerical computation along with the performance of the turbulence model becomes critical at high AOA and Reynolds number.

\section{Physical Problem and Mathematical Formulation}

Figure 1 schematically illustrates the geometry of the AUV bare hull along with the computational domain, indicating different boundaries of the domain. The conventional torpedo-shaped AUV has a circular nose, cylindrical mid-body and a conical aft-body with a blunt stern section. The 3D Cartesian coordinate system used in the study is implemented by placing the coordinate origin at the centre of the nose and the $x$-axis is taken along the length of the vehicle. Therefore, all the axial distances along the body of the hull are calculated with reference to the nose centre. The $z$-axis is taken as the pitching axis.

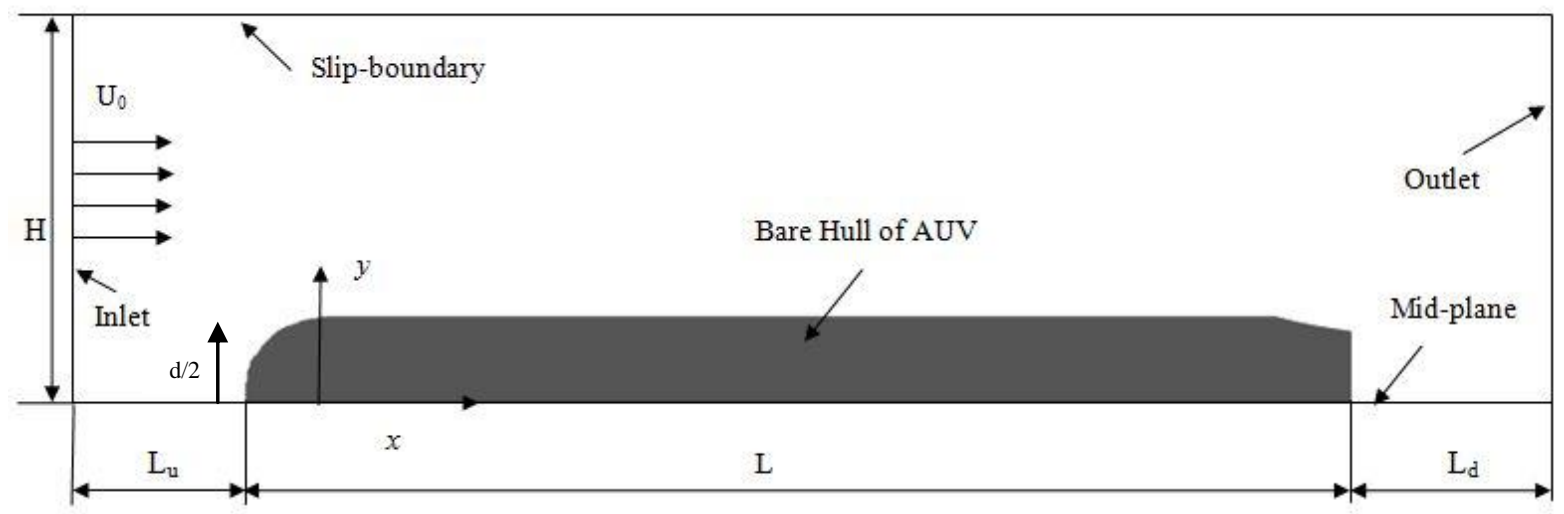

Fig. 1: Schematic of the computational domain (x-y plane) along with the bare hull of the AUV (showing tophalf).

\subsection{Governing equations}

The unsteady, incompressible Reynolds-averaged Navier stokes equation is given by

1. Continuity

$\frac{\partial u_{j}}{\partial x_{j}}=0$

2. Momentum

$\frac{\partial u_{i}}{\partial t}+\frac{\partial u_{j} u_{i}}{\partial x_{j}}=-\frac{1}{\rho} \frac{\partial p}{\partial x_{i}}+v \frac{\partial^{2} u_{i}}{\partial x_{j}^{2}}+\frac{\partial\left(-\overline{u_{i}{ }^{\prime} u_{j}}\right)}{\partial x_{j}}$

3. Transport equations for the SST $\kappa$ - $\omega$ model

$\frac{\partial(\rho \kappa)}{\partial t}+\frac{\partial\left(\rho \kappa u_{i}\right)}{\partial x_{j}}=\frac{\partial}{\partial x_{j}}\left(\Gamma_{\kappa} \frac{\partial \kappa}{\partial x_{j}}\right)+\tilde{G}_{\kappa}-Y_{\kappa}$

$\frac{\partial(\rho \omega)}{\partial t}+\frac{\partial\left(\rho \omega u_{i}\right)}{\partial x_{j}}=\frac{\partial}{\partial x_{j}}\left(\Gamma_{\omega} \frac{\partial \omega}{\partial x_{j}}\right)+G_{\omega}-Y_{\omega}+D_{\omega}$ 
In the above equations, $\tilde{G}_{\kappa}$ represents the generation of turbulent kinetic energy due to mean velocity gradient; $G_{\omega}$ represents the generation of the specific dissipation rate; $\Gamma_{\kappa}, \Gamma_{\omega}$ represents the effective diffusivity of $\kappa$ and $\omega$ respectively. $Y_{\kappa}$ and $Y_{\omega}$ are dissipation of $\kappa$ and $\omega$ due to turbulence while $D_{\omega}$ being the cross-diffusion term. The details of the respective terms in the SST $\kappa$ - $\omega$ model can be found in Fluent user's guide (Ansys Fluent, 2009) and not repeated here for the purpose of brevity.

The SST $\kappa$ - $\omega$ model (Ansys Fluent, 2009) combines the accurate near-wall treatment of the $\kappa$ - $\omega$ method with the free-stream independence of the $\kappa$-emethod by using a blending function; thus it enables the model to switch between the standard $\kappa-\omega$ model near the wall and standard $\kappa$ - $\varepsilon$ model in the far-field. The model includes a cross-diffusion term in the wequation. Also, the expression for turbulent viscosity is modified to account for the transport of the turbulent shear stress. The use of a $k$ - $\omega$ formulation in the inner parts of the boundary layer makes the model directly usable all the way down to the wall through the viscous sub-layer; hence the SST $k-\omega$ model can be used as a low-Re turbulence model without any extra damping functions.

\subsection{Boundary conditions}

A uniform flow $\left(u=u_{\infty}\right)$, with known values of free-stream turbulence parameters given as $I_{\infty}=0.02 \%$, $l_{t, \infty}=0.07 l$; where $I_{\infty}=$ turbulence intensity, $l_{t, \infty}=$ turbulence length scale, is prescribed at the inlet. At the upper boundary, free-slip boundary condition is specified $\left(\frac{\partial u}{\partial y}=v=0\right)$. At the outlet, the outflow boundary condition, given by $\left(\frac{\partial u}{\partial x}=\frac{\partial v}{\partial x}=0\right)$ with zero turbulence $(k=\omega=0)$, is imposed. At the solid wall of the hull, the widely used wall boundary conditions $(u=v=0)$ is used. At the axis, the symmetry condition of zero-shear stress $\left(\frac{\partial u}{\partial y}=0\right)$ is specified.

\subsection{Hydrodynamic coefficients}

The study aims to estimate the variations of some important hydrodynamic coefficients which are of particular significance in underwater vehicles. The most important of these parameters are the different drag forces which are characterized by the corresponding drag force coefficients. The total drag acting on an object having a relative motion with a fluid is composed of the pressure and the viscous drag. Therefore, the total drag coefficient is given as $C_{D}=2 F_{D} / \rho A u_{\infty}^{2}$ and thenormal force coefficient is calculated as $C_{L}=2 F_{L} / \rho A u_{\infty}^{2}$. The drag force is calculated along the flow direction while the normal force is acting in a direction perpendicular to the flow. The reference area considered in the first case is the maximum frontal area of the hull whereas in eq. (6), it represents the maximum planform area of the hull.

\section{Solution Methodology}

A finite volume based commercial CFD package Ansys Fluent (2009) is employed to obtain the solution of the Reynolds-averaged Navier-Stokes equations. The pressure based numerical scheme, which solves the discretized governing equations sequentially, is selected. The coupling between the pressure and velocity fields is achieved using the SIMPLE algorithm. A second-order upwind scheme for the convection, the centraldifferencing scheme for the diffusion terms and the first-order implicit scheme for the temporal discretization are employed.The algebraic equations are solved by using the Gauss-Siedel point-by-point iterative method in conjunction with the Algebraic Multigrid (AMG) solver. An absolute convergence criterion of $10^{-6}$ is set for all the discretized equations. For the calculation of the unsteady flow field, the time step size for all the computations is considered as $(\Delta \mathrm{t})=10^{-3} \mathrm{~s}$.

\subsection{Domain description}

The mesh on the surface of the AUV hull is presented with a closer view in Fig. 2(a). The entire study is conducted considering two different computational domains around the AUV hull (Shaktivel et al., 2011). Initially, the zero angle of attack case is solved using a smaller base domain $(5.77 \mathrm{Lx} 0.625 \mathrm{~L} \mathrm{x} 0.625 \mathrm{~L})$ and structured H-type grid is used in this domain as shown in Fig. 2(b). The smaller size of the domain and grid 
reduce the computational cost for the initial study. However, for angle of attack studies, the vehicle is placed inside a much larger cylindrical domain $(11 \mathrm{Lx} 5.88 \mathrm{Lx} 5.88 \mathrm{~L})$ which is necessary to capture the changes in the flow pattern associated with non-zero incidence angle. Within the cylindrical domain, body-fitted O-type grid is generated, which is shown in Fig. 2(c).

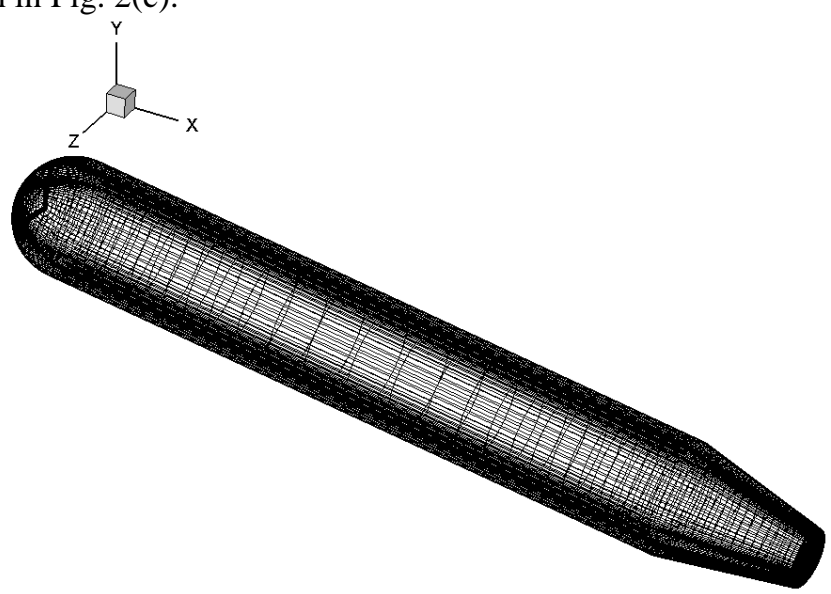

(a)

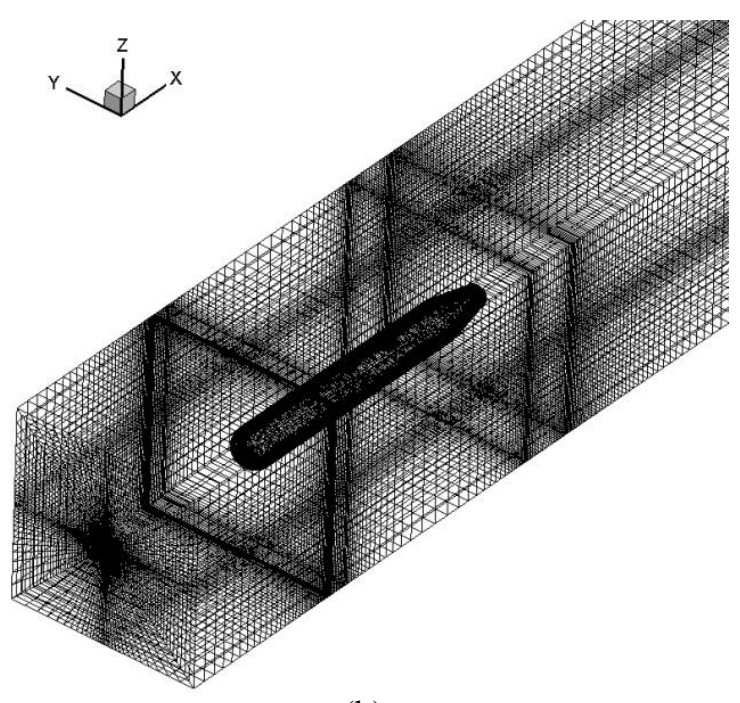

(b)

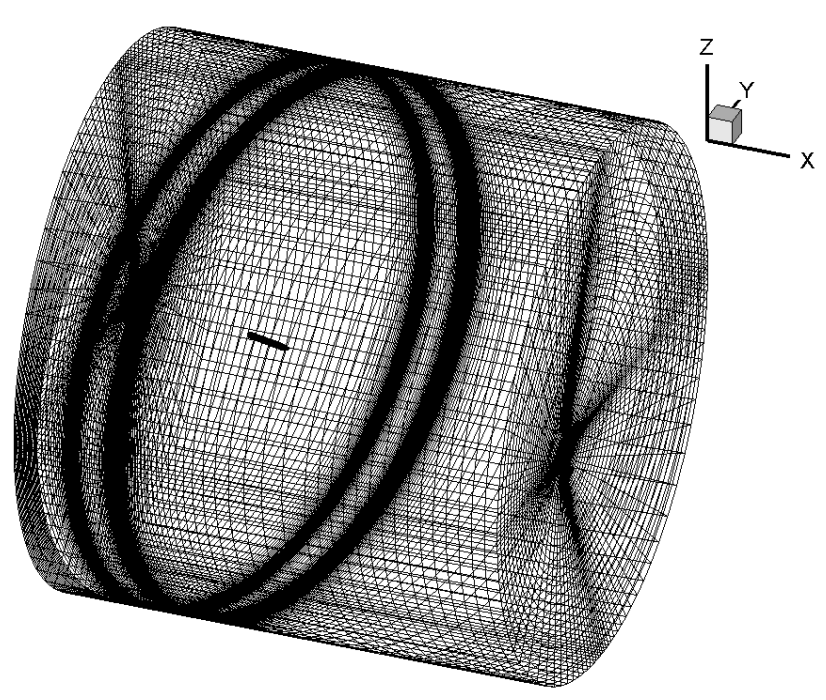

(c)

Fig. 2: (a) Grid within the base domain for zero angle of attack, (b) enlarged view of grid on the AUV hull surface and (c) structured grid within the flow domain around AUV hull, for nonzero AOA.

The SST $\kappa$ - $\omega$ turbulence model by Menter (1994) with the low-Re correction is used to solve the boundary layer equations. In order to ensure that sufficient numbers of grid points are used to resolve the boundary layer, the turbulence closure model requires that the wall $\mathrm{y}^{+}$parameters must satisfy a certain criterion, where $y^{+}=\frac{y u_{\tau}}{v}$, where $u_{\tau}=\sqrt{\frac{\tau}{\rho}}$ is the friction velocity. By keeping the grid points near the wall of the vehicle sufficiently close, wall $\mathrm{y}^{+}<40$ is maintained which is supposed to produce accurate results with the turbulence model used. The distribution of the wall $\mathrm{y}^{+}$parameter for representative angle of attack $\left(\alpha=10^{\circ}\right)$ is illustrated in Fig. 3 . 


\section{Results and Discussion}

\subsection{Model validation}

The geometry of the widely-studied DREA bare hull (Karim et al., 2008) is selected for the purpose of validating the numerical model. The zero-degree AOA results are compared against the CFD results by Karim et al. (2008) as well as with the computational results of Baker(2004) and the original experimental results of Mackay (1988). The results of the validation are presented in Fig. 4 and in Table 1. The results show a satisfactory matching of the present simulation results with those of the previous works.

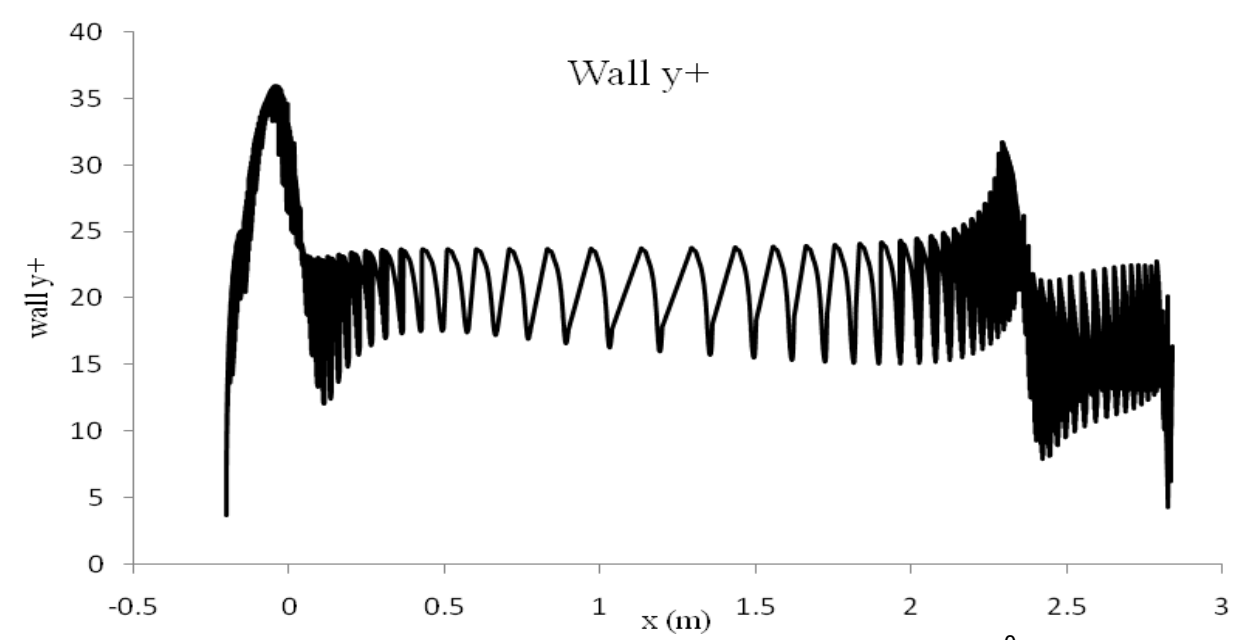

Fig. 3: Wall $\mathrm{y}^{+}$distribution along the body of the 3D AUV hull at $10^{0}$ angle of attack.

Table 1: Comparison of $C_{D}$ values of present work with previous results $\left(\alpha=0^{\circ}\right)$

\begin{tabular}{|c|c|c|c|c|}
\hline Parameter & Experimental (1988) & Baker (2004) & Karim et al. (2008) & Present Study \\
\hline $\mathrm{C}_{\mathrm{D}}$ & 0.00123 & 0.00167 & 0.00104 & 0.00153 \\
& \pm 0.000314 & & & \\
\hline
\end{tabular}

\subsection{Effect of angle of attack}

To simulate the vehicle inclined to the incoming flow while continuing forward motion, the model is studied under different angles of attack ranging between $0^{0} \leq \alpha \leq 20^{\circ}$, as explained in Fig. 1(b), for different surge conditions. The latter criterion is characterised by the Reynolds number based on the vehicle length for the range of $1.53 \times 10^{6} \leq \operatorname{Re} \leq 9.18 \times 10^{6}$. The results of the simulation, presented through Figs. 5 to 9 and Tables 2 and 3 illustrate the effect of the different extent of pitching on the aerodynamic performance of the vehicle. Fig. 5 presents the variation of the hydrodynamic forces acting on the vehicle at different kinematic conditions. Fig. 5(a) and (b) are the variations of the drag and lift coefficients respectively with angle of attack for a fixed Reynolds number $\operatorname{Re}=3.06 \times 10^{6}$. Since negative pitching is found to produce drag and lift forces which are almost identical to those corresponding to the positive pitching conditions, the coefficient values for ( $\alpha<0^{0}$ ) are not plotted here. Another relevant variation of parameter is presented in Fig. 6 . Here, the changes in the coefficients are plotted against Reynolds number. The figure characterizes the dynamics of the motion within the operating range and depicts a decreasing trend in $C_{D}$ and $C_{L}$ with Reynolds number. While for smaller value of the angle of attack, the variation is negligible and almost linear; for the maximum pitch, the nonlinearity in the flow is evident from the figure which also indicates a significant variation in the flow as the Reynolds number is changed. The symmetry of pitching motion about the level-condition $\left(\alpha=0^{0}\right)$ of the vehicle may be appreciated through Fig. 7. This figure illustrates the variation of the lift coefficient with the drag coefficient for two representative values of Reynolds number. The negative values of the lift coefficient indicate negative pitching condition of the vehicle. 


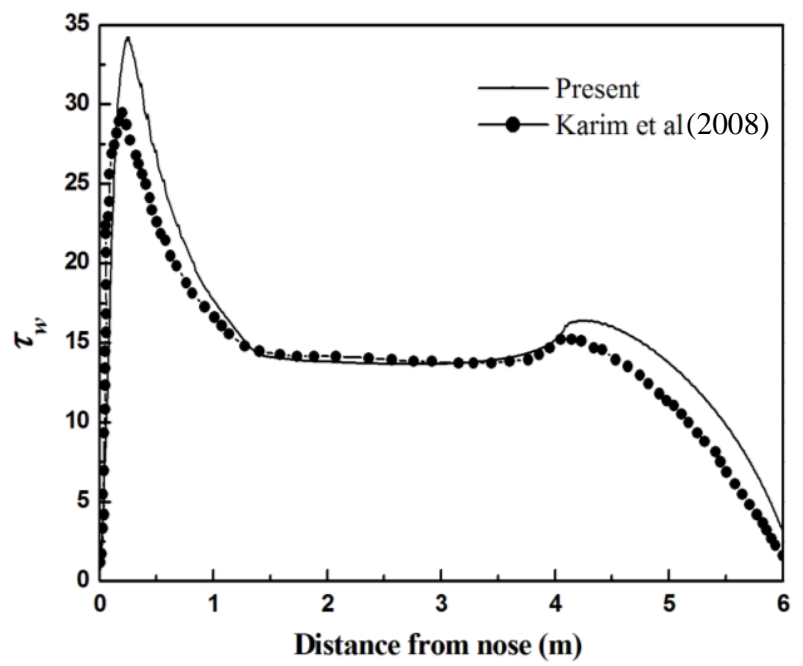

(a)

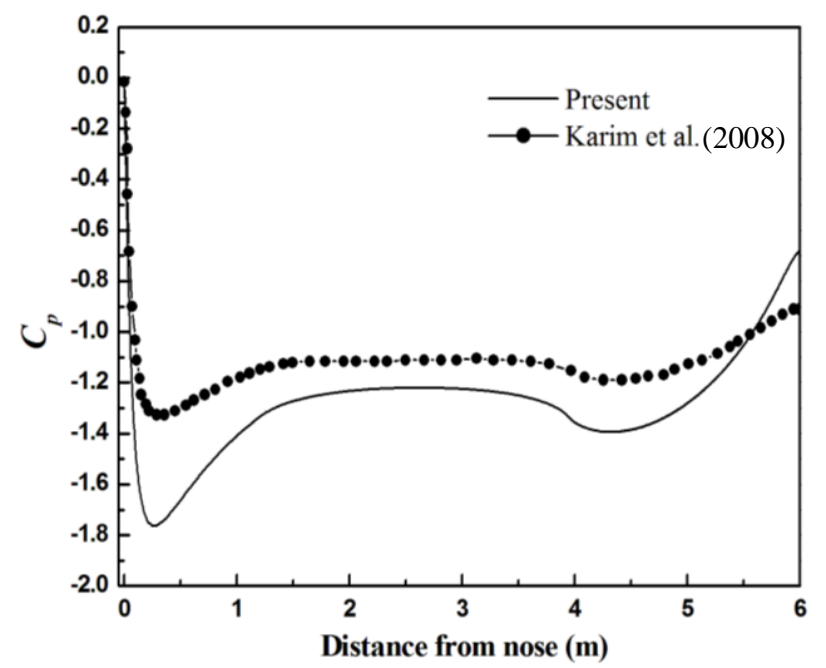

(c)

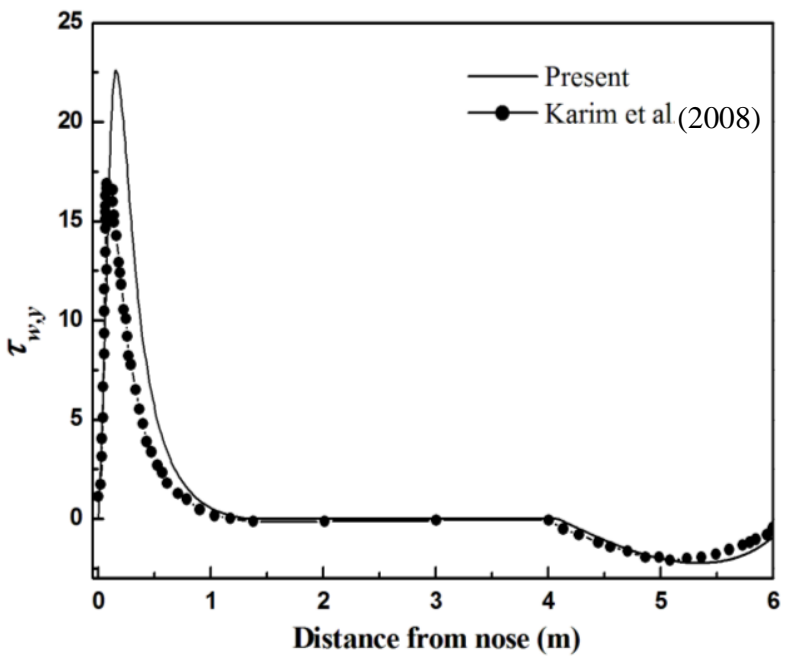

(b)

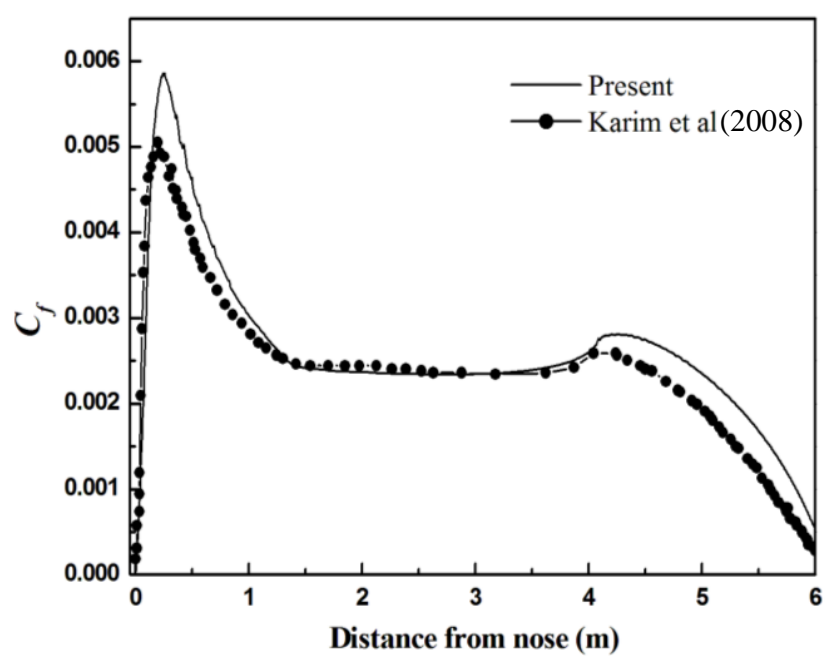

(d)

Fig. 4: Validation of results with Karim et al. (2008) (a) wall shear stress $\left(\tau_{w}\right)$, (b) y-wall shear stress $\left(\tau_{w, y}\right)$ (c) coefficient of pressure $\left(C_{p}\right)$, and $(\mathrm{d})$ skin friction coefficient $\left(C_{f}\right)$ with zero degree angle of attack.

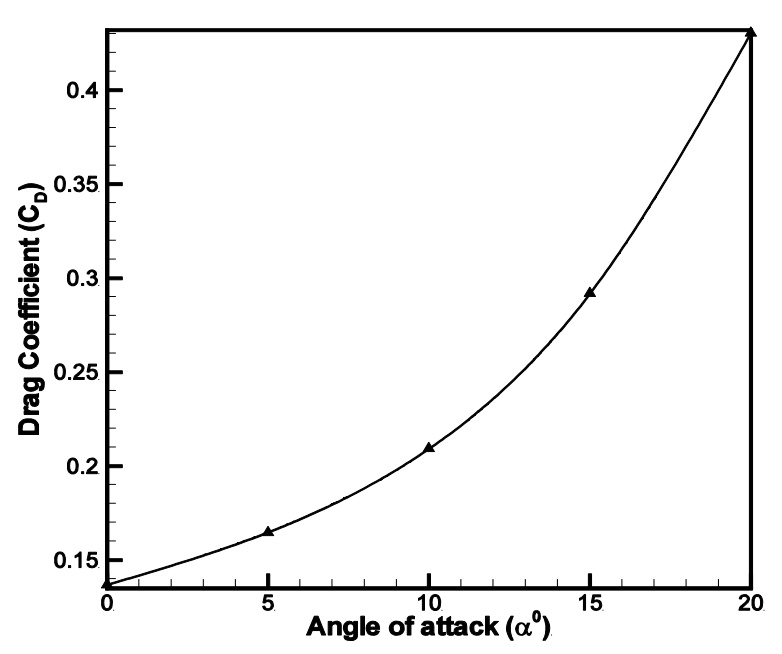

(a)

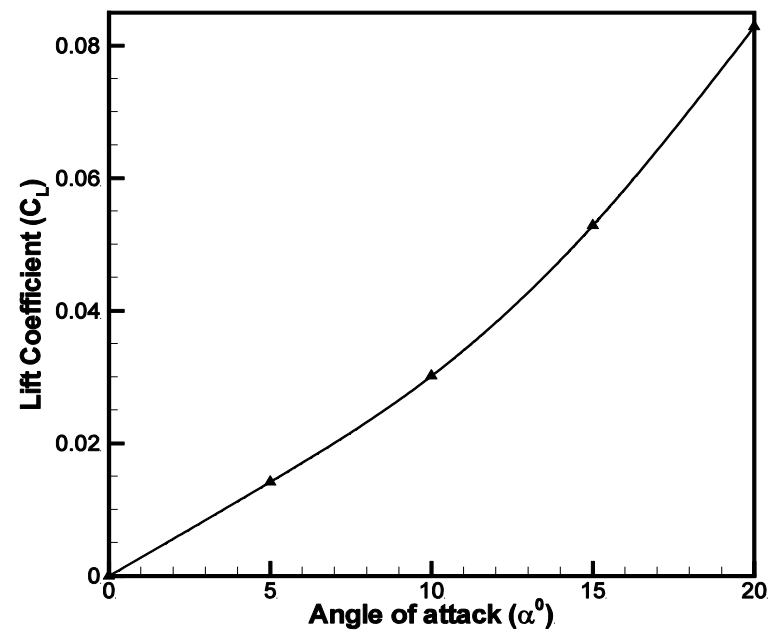

(b)

Fig. 5: Variations of hydrodynamic force coefficients with angle of attack for $\operatorname{Re}=3.06 \times 10^{6}$. 


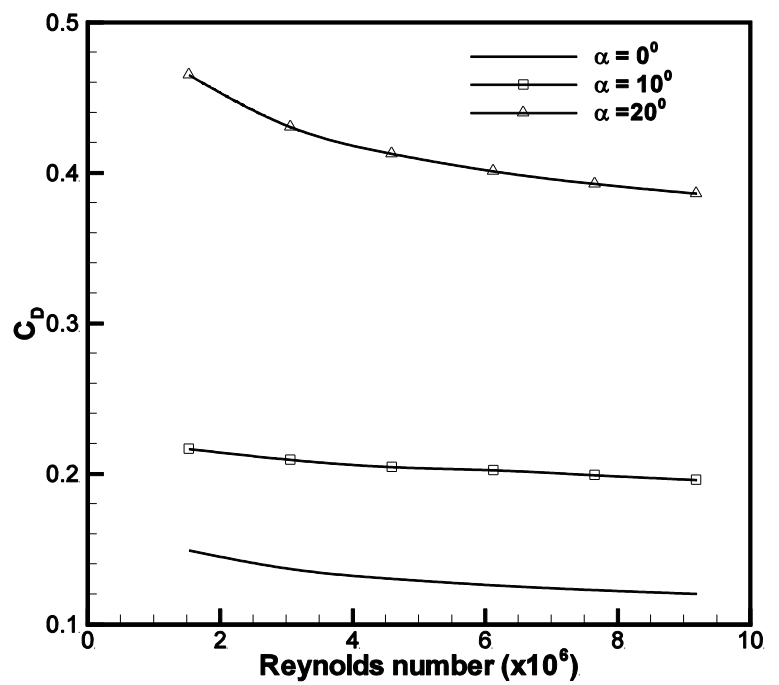

(a)

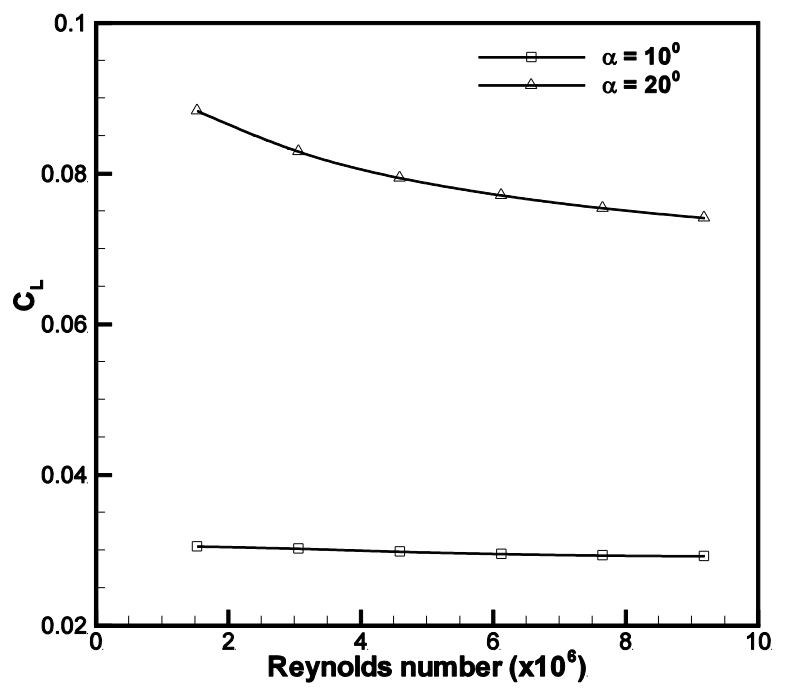

(b)

Fig. 6: Variation of hydrodynamic force coefficients with Reynolds number, (a) drag coefficient, (b) lift coefficient.

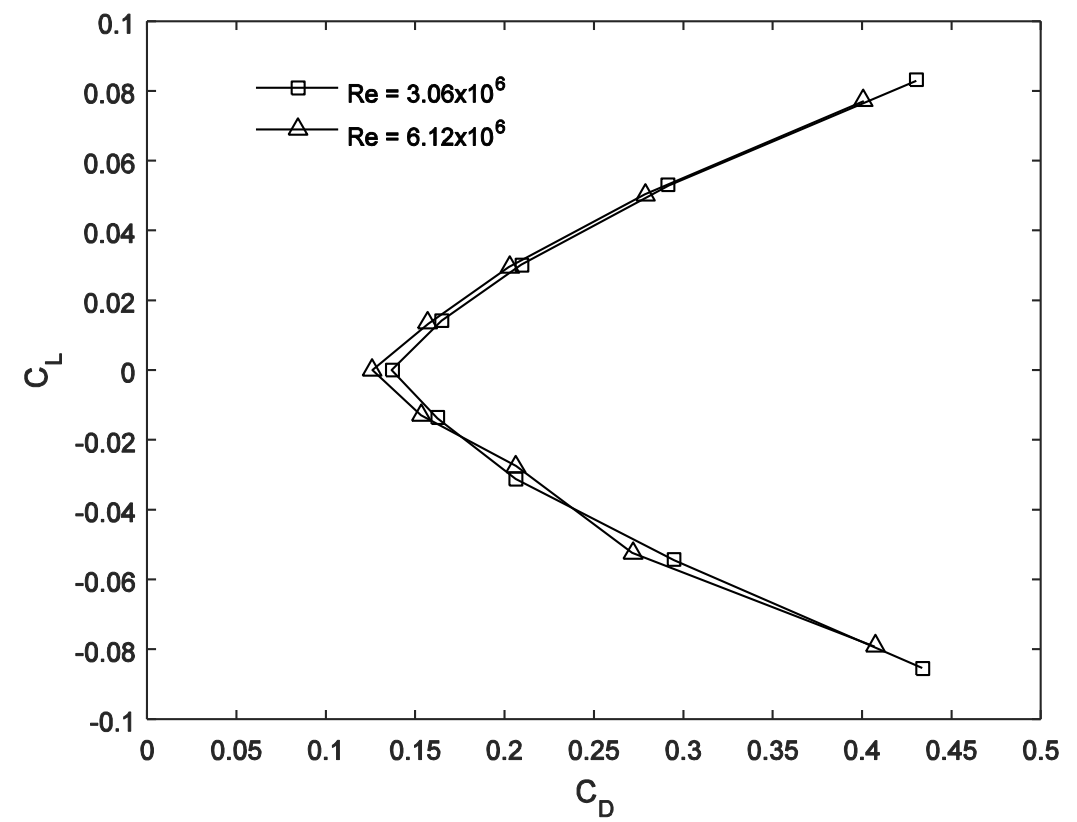

Fig. 7: Plot of lift coefficient against drag coefficient for two different Reynolds numbers.

Table 2: Drag force and drag coefficient $\left(\mathrm{C}_{\mathrm{D}}\right)$

\begin{tabular}{|c|c|c|c|c|}
\hline \multirow{2}{*}{$\begin{array}{c}\text { Angle of attack } \\
\text { (degree) }\end{array}$} & \multicolumn{2}{|c|}{$\mathrm{V}=1 \mathrm{~m} / \mathrm{s}$} & $\mathrm{F}_{\mathrm{D}}(\mathrm{N})$ & $\mathrm{C}_{\mathrm{D}}$ \\
\cline { 2 - 5 } & $\mathrm{F}_{\mathrm{D}}(\mathrm{N})$ & $\mathrm{C}_{\mathrm{D}}$ & 34.9059 & 0.126 \\
\hline 0 & 9.4768 & 0.1368 & 43.619 & 0.1574 \\
5 & 11.4097 & 0.1647 & 56.0896 & 0.2025 \\
10 & 14.4996 & 0.2094 & 77.2005 & 0.2787 \\
20 & 20.223 & 0.292 & 111.1147 & 0.4011 \\
\hline
\end{tabular}


Table 3: Lift force and lift coefficient $\left(\mathrm{C}_{\mathrm{L}}\right)$

\begin{tabular}{|c|c|c|c|c|}
\hline \multirow{2}{*}{$\begin{array}{c}\text { Angle of attack } \\
\text { (degree) }\end{array}$} & \multicolumn{2}{|c|}{$\mathrm{V}=1 \mathrm{~m} / \mathrm{s}$} & $\mathrm{F}_{\mathrm{L}}(\mathrm{N})$ & $\mathrm{C}_{\mathrm{L}}$ \\
\cline { 2 - 5 } & $\mathrm{F}_{\mathrm{L}}(\mathrm{N})$ & $\mathrm{C}_{\mathrm{L}}$ & 0 & 0 \\
\hline 0 & 0 & 0 & 34.243 & 0.0133 \\
5 & 9.1423 & 0.0142 & 76.2113 & 0.0295 \\
10 & 19.4784 & 0.0302 & 129.9723 & 0.0504 \\
15 & 34.1453 & 0.0529 & 198.9348 & 0.0771 \\
\hline
\end{tabular}

The static pressure variations over the length of the vehicle are presented through Figs. 8 and 9. The change in pressure along the length of the vehicle is shown in Fig. 8. The locations chosen for the measurement of these pressure values are termed as suction side and pressure side, as usually denoted, which are the $0^{\circ}$ and $180^{\circ}$ angular locations around the hull as indicated in Fig. 9(a) for proper visualization. Since no upward pressure thrust is possible at level-condition, the flow should not exhibit any asymmetry for the two sides in terms of pressure distribution. Indeed, it shows no asymmetry and only one curve of pressure distribution is present for this case. For the other cases, a higher negative pressure is always observed for the pressure side. The difference between the pressure forces on the two sides is responsible for generation of the upward lift since shear stress plays an insignificant role. A general mechanism of the pressure variation may be given as follows; the pressure is always the maximum at the stagnation point on the nose. Due to the curvature in the nose geometry, the pressure then gradually decreases as the fluid rises over the hemisphere. Thereafter, due to the flat, cylindrical shape of the mid-body, no significant variations in pressure can be observed. Even, the effect of angle of attack is very insignificant in this distribution. The pressure valley at the end is again due to the converging shape of the tail-section and blunt aft, along which the pressure generally increases. It may be appreciated that the nose geometry is responsible for most of the pressure variation along the hull, which causes the drag on the body. Although this shape of hemispherical nose is chosen due to the manufacturing and payload considerations, it is not hydro-dynamically most efficient.

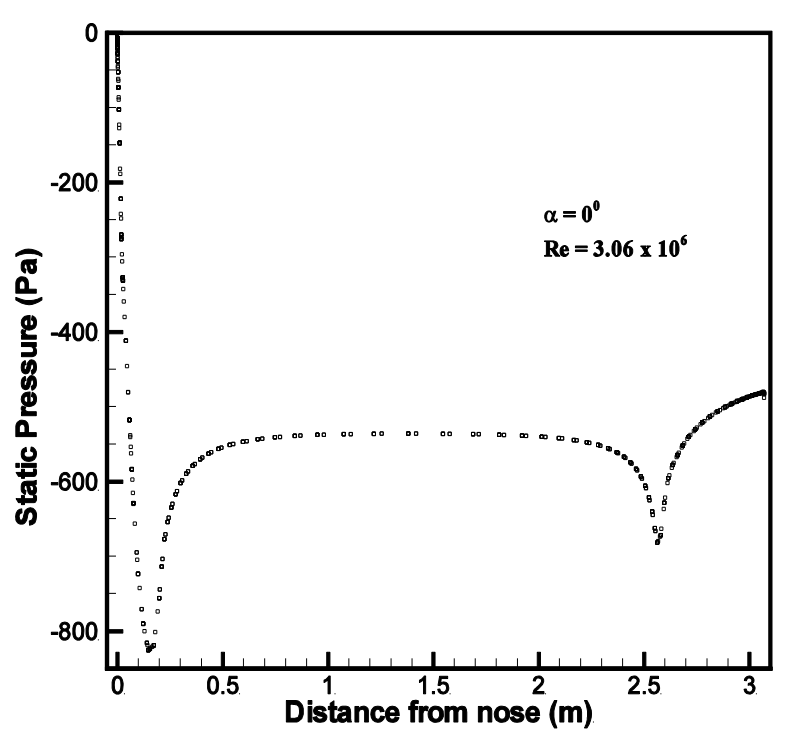

(a)

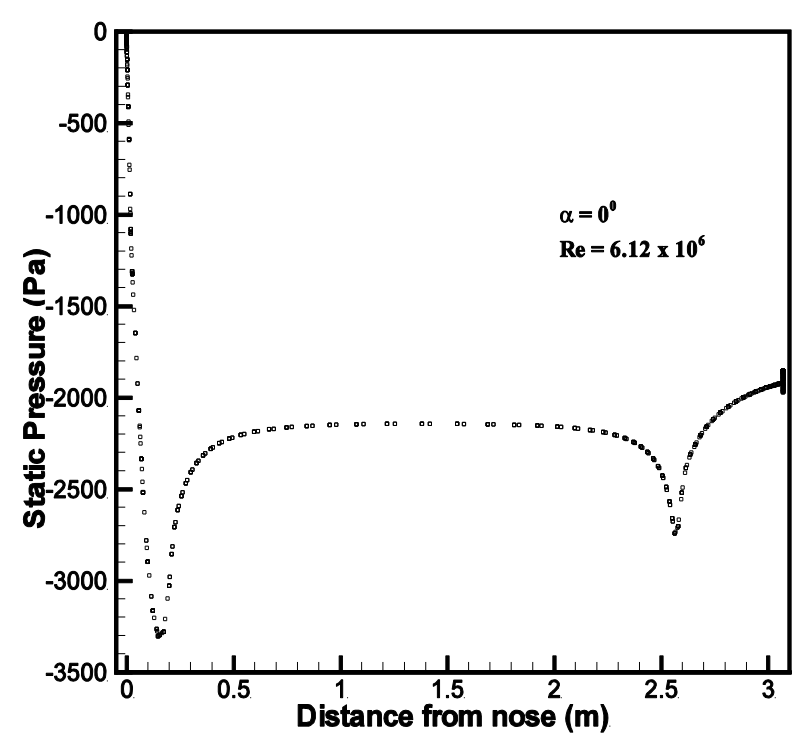

(b)

Fig. 8: Pressure distribution along the length of the AUV hull at an angle of attack, $\alpha=0^{0}$ for a) $\operatorname{Re}=3.06 \times 10^{6}$ and b) $\operatorname{Re}=6.12 \times 10^{6}$. 


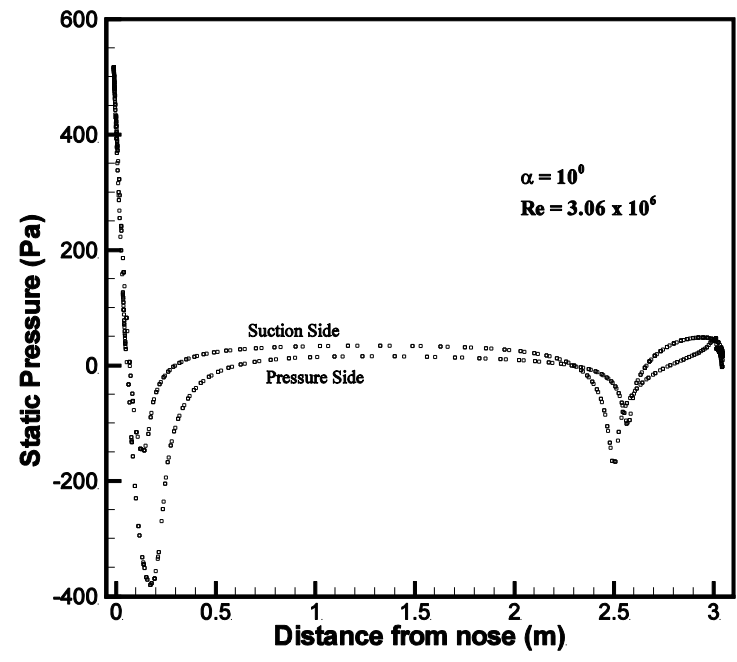

(c)

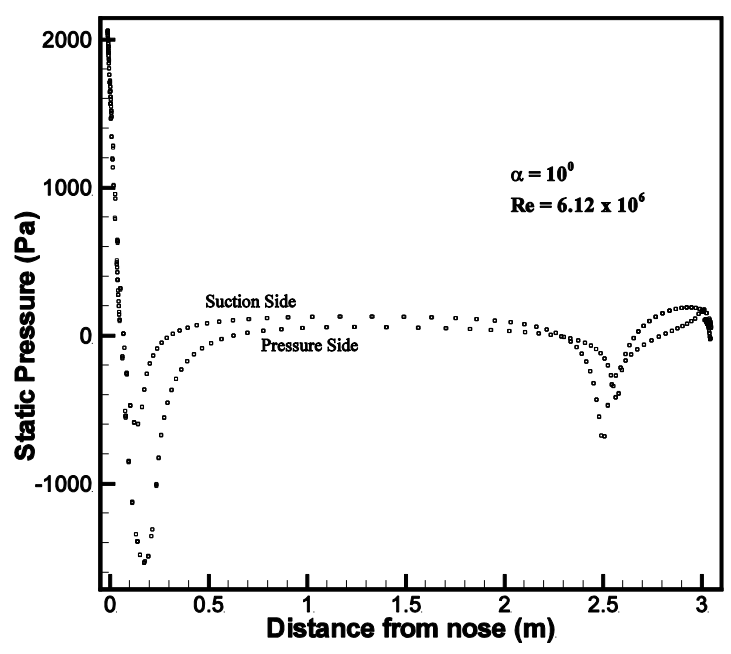

(d)

Fig. 8: Pressure distribution along the length of the AUV hull at an angle of attack, $\alpha=10^{0}$ for c) $\operatorname{Re}=3.06 \times 10^{6}$ and d) $\operatorname{Re}=6.12 \times 10^{6}$.

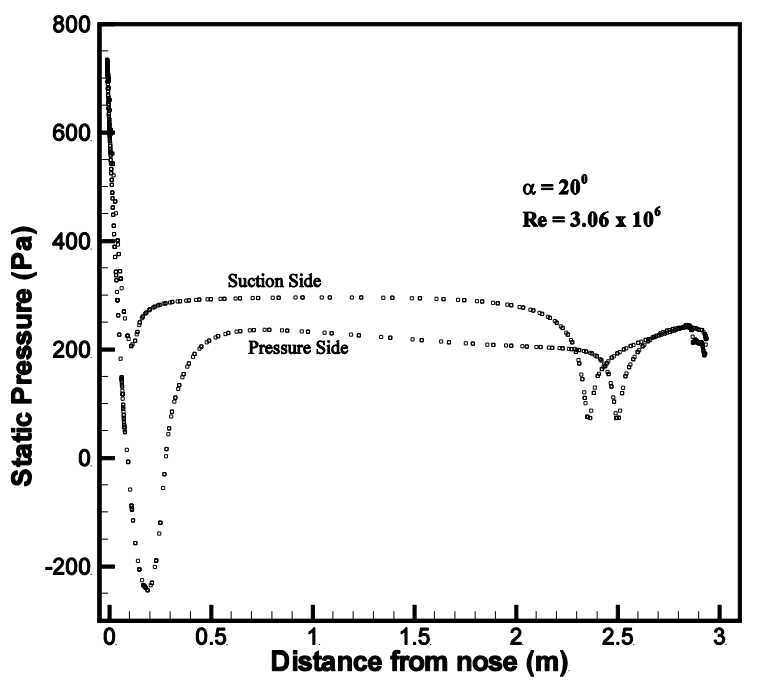

(e)

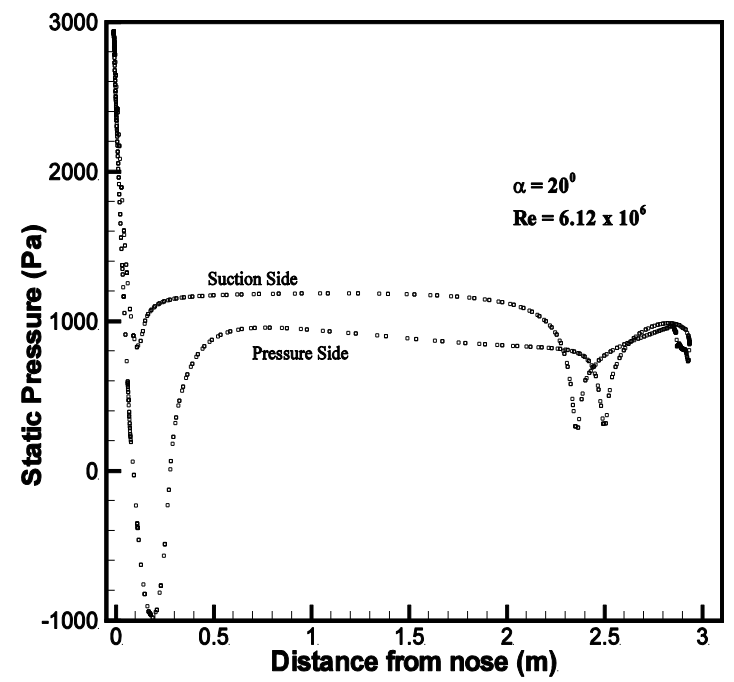

(f)

Fig. 8: Pressure distribution along the length of the AUV hull at an angle of attack, $\alpha=20^{\circ}$ for e) $\operatorname{Re}=3.06 \times 10^{6}$ and f) $\operatorname{Re}=6.12 \times 10^{6}$.

Figure 9 describes the variation of the static pressure around the circumference of the hull at two different locations for different angles of attack. The two locations where the pressure data is taken are the middle of the cylindrical mid body and the section where the aft-body is attached to the mid-section of the hull, often referred to as the stern plane. As may be expected for the flow to be absolutely symmetrical about the perimeter of the hull, no pressure variation should be present around the circumference. This is of course the case for zero angle of attack, where the flow is essentially two-dimensional and no significant pressure variation may be observed for the highest $R e$ values. However, at larger angles of attack condition, the flow exhibits three-dimensional properties around the hull and appreciable variations of pressure due to the cross-flow are observed for these cases. Depending on the location, the nature and magnitude of these variations are different. However, their presence is consistent for high angle of attack flows which are expected to be non-linear.

In Fig. 10, an effort is made to depict the streamlines around the body of the hull for better understanding of the nature of the flow field at various angles of attack. In the absence of cross flow, the streamlines remain parallel to the direction of the dominating flow which is also called as stream-wise direction. However, as made evident from Fig. 9, for $\alpha=10^{\circ}$ or higher, the flow possess significant amount of cross-flow which bends the streamlines towards the suction side of the hull. The streamlines converge near the suction side and separates 
from the surface as the angle of attack is increased. Therefore, the converged streamlines represent the line of separation of the flow from the surface. As the angle of attack increases, due to the higher adverse pressure gradient, the point of convergence of the streamlines progresses along the body of the hull towards the nose, thereby accelerating the separation. Even without the presence of the cross-flow, as angle of attack is increased, the flow is bound to separate from the surface due to the adverse pressure gradient the incoming flow might experience. A better design of the hull body ensures the delay of this separation, which increases the pressure drag by creating a low-pressure region in the wake of the separation, at higher angles of attack.

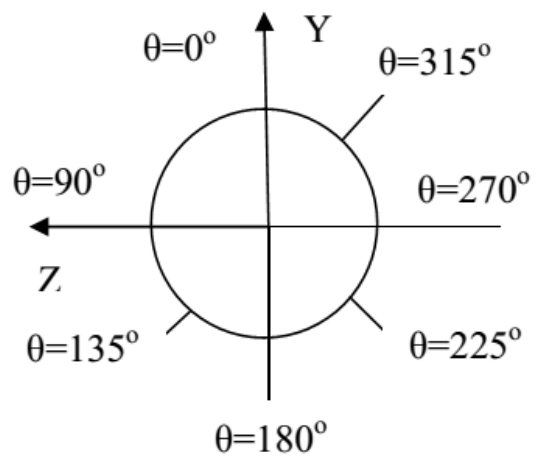

(a)

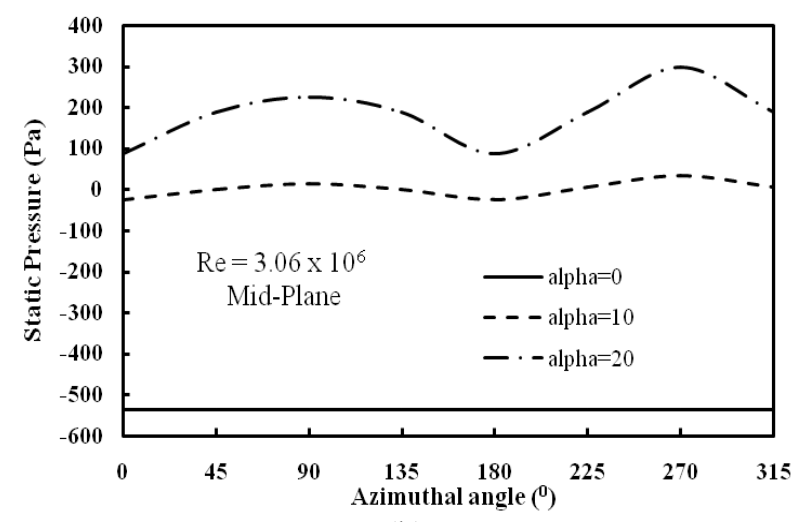

(b)

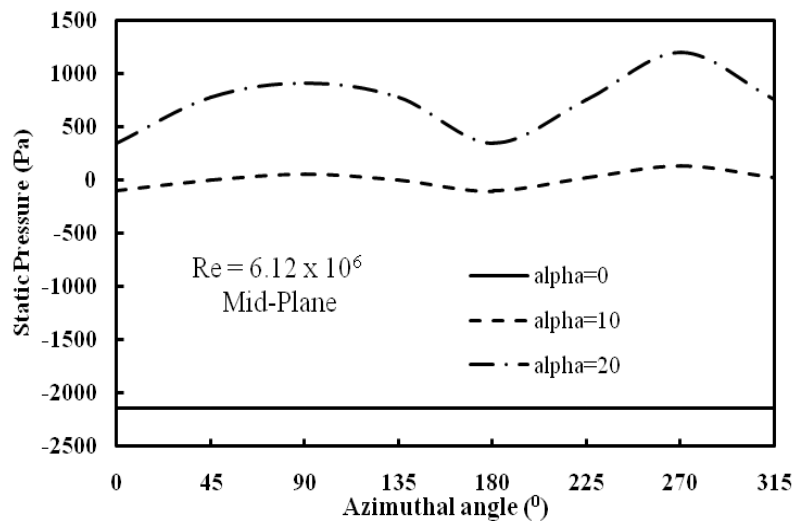

(d)

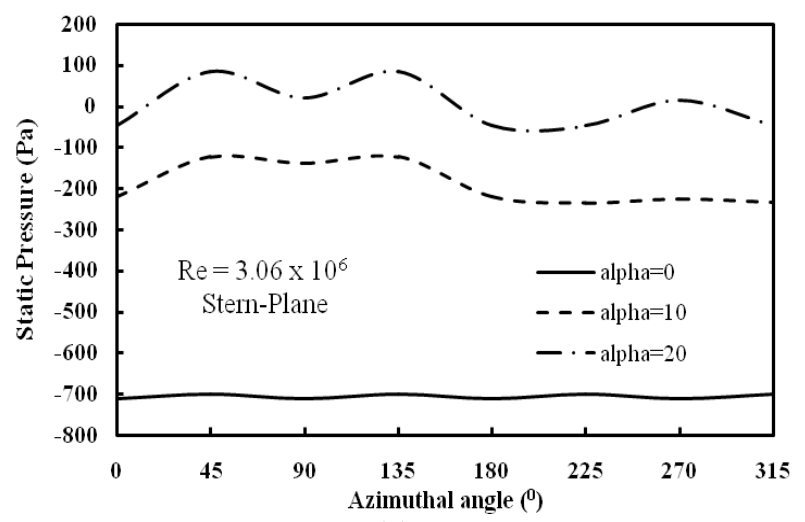

(c)

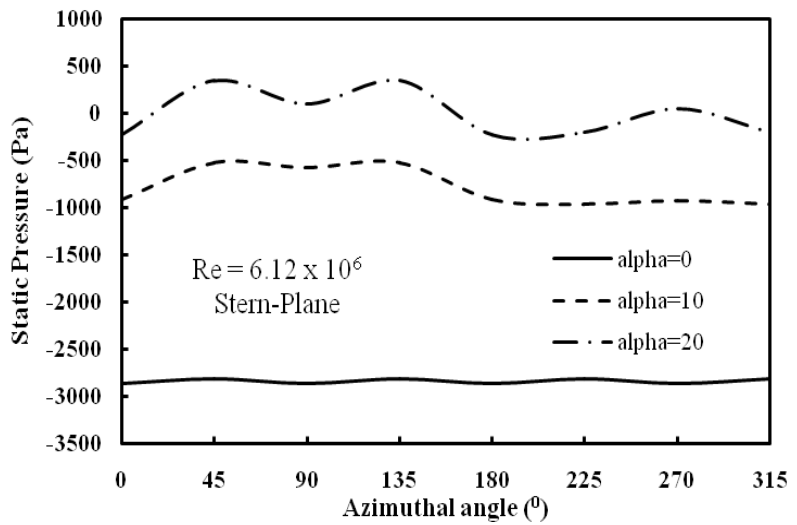

(e)

Fig. 9: (a) Angular position around the hull, (b)-(d) Variation of the static pressure around hull surface for different angles of attack at the mid-plane (left column) and stern plane (right column) for different Reynolds numbers. 


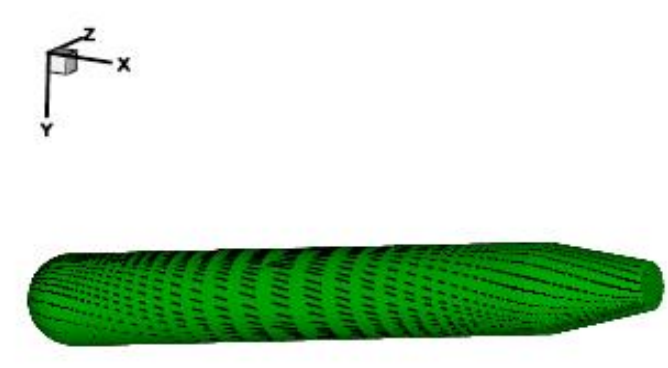

(a)

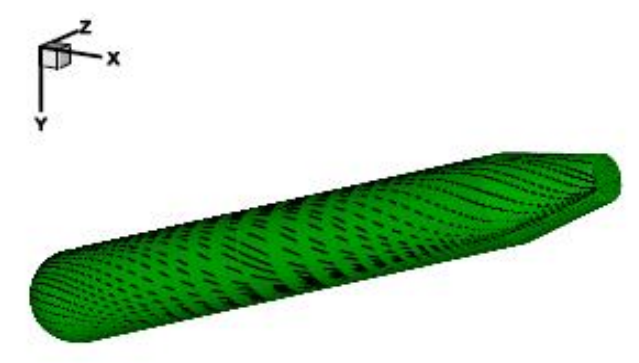

(c)

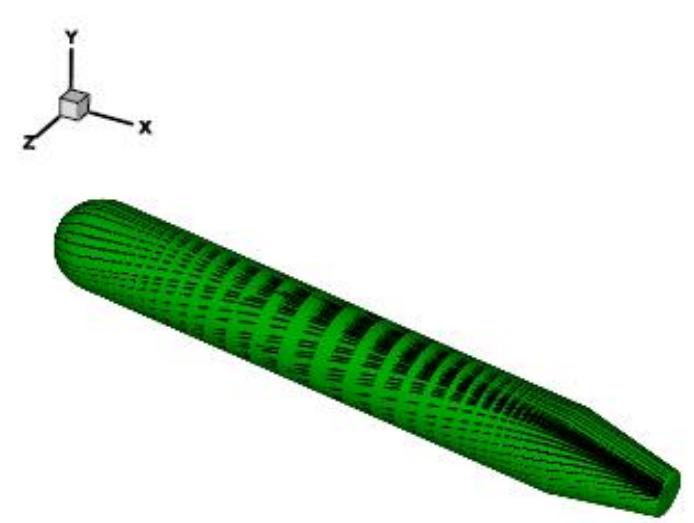

(b)

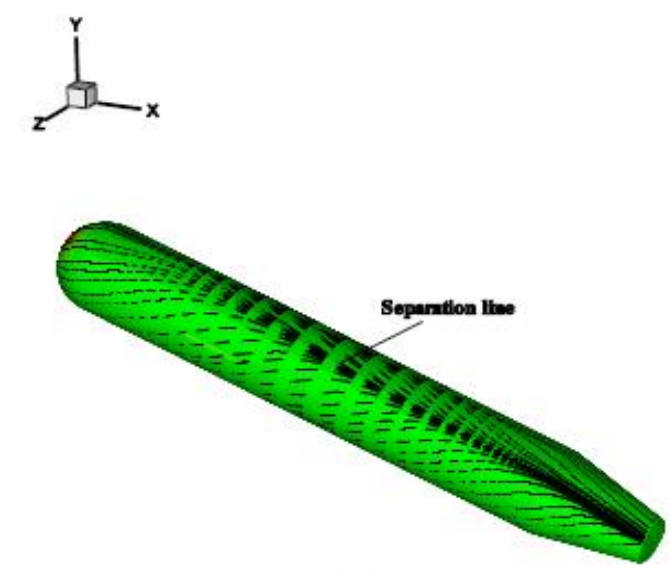

(d)

Fig. 10: Volumetric streamlines on the surface of the AUV for $\mathrm{Re}=6.12 \times 10^{6}$ (a)-(b) $\mathrm{AOA}=10^{0}$, (c)-(d) $\mathrm{AOA}=$ $20^{\circ}$, left column: Pressure Side right column: Suction Side

\section{Conclusions}

For the vehicle motion, both the upward and downward pitching motions are studied, with a range of angle of attack and upstream Reynolds number. The results are presented in terms of the force coefficients and pressure distribution along the length and around the circumference of the hull. It is seen that at high angles of attack, the flow field possesses significant non-linearity and cross-flow components are also found. The threedimensionality of the flow is significant for higher pitching. The circumferential pressure gradient is found to be significant at high angle of attack. Within this parameter range, it is seen that the hydrodynamic force coefficients decrease with the increase in the Reynolds number. The earlier flow separation along the length of the hull compounded with the cross-flow effects results in a non-linear variation of the drag for higher angles of attack.

\section{Acknowledgement}

The work was supported by CSIR, Govt. of India through the XII-th five year plan project "Autonomous under Water Robotics" under Engineering Cluster (project no. ESC0113).

\section{References}

Abdullah, F., Ferraro and M., Rigit, A. (2007): Design Optimisation of an Unmanned Underwater Vehicle, Journal of Engineering Science and Technology, 2, 119-125.

ANSYS CFX-Solver Theory Guide. Release 12.1, (2009): ANSYS, Inc.

ANSYS Fluent-Solver Theory Guide. Release 14.0, (2009): ANSYS Inc. 
Baker, C. (2004): Estimating Drag Forces on Submarine Hulls, Contract Report, DRDC Atlantic, CR 2004-125. Cairns, J., Larnicol, E., Ananthakrishnan, P., Smith, S. and Dunn, S. (1998): Design of AUV Propeller Based on a Blade Element Method, OCEANS '98 Conference, (IEEE, New York), 2, 672-675.

de Barros, E. A., Dantas, J. L. D., Pascoal, A. M. and de Sa, E. (2008): Investigations of Normal Force and Moment Coefficients for an AUV at Nonlinear Angle of Attack and Sideslip Range, IEEE Journal of Oceanic Engineering, 33, 538-549. http://dx.doi.org/10.1109/JOE.2008.2004761

Gomatam, S., Vengadesan, S. and Bhattacharyya, S. K. (2012): Numerical Simulations of Flow Past an Autonomous Underwater Vehicle at Various Drift Angles, Journal of Naval Architecture and Marine Engineerin, 9, 135-152. http://dx.doi.org/10.3329/jname.v9i2.12567

Hu, Z. and Lin, Y. (2008): Computing The Hydrodynamic Coefficients of Underwater Vehicles Based on Added Momentum Sources, $18^{\text {th }}$ International Offshore and Polar Engineering Conference, Canada, 451-456.

Husaini, M., Samad, Z. and Arshad, M. R. (2011): Autonomous Underwater Vehicle Propeller Simulation using Computational Fluid Dynamics, Computational Fluid Dynamics Technologies and Applications, InTech, 293314.

Husaini, M., Samad, Z. and Arshad, M. R. (2009): CFD Simulation of Co-Operative AUV Motion, Indian journal of marine sciences, 38, 346-351.

Jagadeesh, P. and Murali, K. (2005): Applications of Low-Re Turbulence Models for Flow Simulations Past Underwater Vehicle Hull Forms, Journal of Naval Architecture and Marine Engineering, 1, 41-54.

Jagadeesh, P. and Murali, K. (2006): Investigations on Alternative Turbulence Closure Models for Axisymmetric Underwater Hull Forms, Maritime Emergency Management, 1, 36-57.

Jagadeesh, P., Murali, K. and Idichandy, V. G. (2009): Experimental Investigation of Hydrodynamic Force Coefficients over AUV Hull Form, Ocean Engineering, 36, 113-118. http://dx.doi.org/10.1016/j.oceaneng.2008.11.008

Karim, M. M., Rahman, M. M. and Alim, M. A. (2008): Numerical Computation of Viscous Drag for Axisymmetric Underwater Vehicles, JurnalMekanikal, 26, 9-21.

Karim, M. M., Rahman, M. M. and Alim, M. A. (2011): Performance of SST k- $\omega$ Turbulence Model for Computation of Viscous Drag of Axisymmetric Underwater Bodies, International Journal of Engineering, Transactions B: Applications, 24, 139-146.

Kim, J., Kim, K., Choi, H. S., Seong, W. and Lee, K.-Y. (2002): Estimations of Hydrodynamic Coefficients for an AUV using Nonlinear Observers, IEEE Journal of Oceanic Engineering, 27, 830-840. http://dx.doi.org/10.1109/JOE.2002.805098

Mackay, M. (1988): Flow Visualization Experiments with Submarine Models in a Wind Tunnel, Department of Research and Development Canada-Atlanta, National Defence- Ottawa, Canada.

Menter, F. R. (1994): Two-Equation Eddy-Viscosity Turbulence Models for Engineering Applications, AIAA Journal, 32, 1598-1605. http://dx.doi.org/10.2514/3.12149

Philips, A. B., Turnock, S. R. and Furlong, M. (2008): Comparisons of CFD Simulations and In-Service Data for the Self Propelled Performance of an Autonomous Underwater Vehicle, 27 ${ }^{\text {th }}$ symposium on Naval Hydrodynamics, Korea.

Philips, A. B., Turnock, S. R. and Furlong, M. (2010): The use of Computational Fluid Dynamics to Aid CostEffective Hydrodynamic Design of Autonomous Underwater Vehicles, Proceedings IMechE, Part M: Journal of Engineering for the Maritime Environment, 224, 239-254.

Sarkar, T., Sayer, P. G. and Fraser, S. M. (1997): Flow Simulation Past Axisymmetric Bodies using Four Different Turbulence Models. Applied Mathematical Modelling, 21, 783-792.http://dx.doi.org/10.1016/S0307904X(97)00102-9

Seo, D. C., Jo, G. and Choi, H. S. (2008):.Pitching Control Simulations of an Underwater Glider using CFD Analysis. OCEANS $2008 \quad-\quad$ MTS/IEEE Kobe Techno-Ocean, (IEEE, Kobe), $1 \quad-\quad 5$. http://dx.doi.org/10.1109/OCEANSKOBE.2008.4530978

Shaktivel, R., Vengadesan, S. and Bhattacharyya, S. K. (2011): Applications of Nonlinear k- $\varepsilon$ Model in Flow Simulation over Underwater Axisymmetric Hull at Higher Angles of Attack, Journal of Naval Architecture and Marine Engineering, 8, 149-163.

Sheerena, S. G., Vengadesan, S. and Bhattacharyya, S. K. (2013): CFD Study of Drag Reduction in Axisymmetric Underwater Vehicles using Air Jets, Engineering Applications of Computational Fluid Mechanics, 7, 193-209. http://dx.doi.org/10.1080/19942060.2013.11015464

Zhang, H. and Wang, S. (2007): Modelling and Analysis of an Autonomous Underwater Vehicle Via MultiBody System Dynamics, $12^{\text {th }}$ IFToMM World Congress, France. 